\title{
Prevention of MSD by means of ergonomic risk assessment (tools) in all phases of the vehicle development process
}

\author{
Schaub Karlheinz, Kugler Michaela, Bierwirth Max, Sinn-Behrendt Andrea and Bruder Ralph \\ Institute of Ergonomics, Darmstadt University of Technology, Petersenstr. 30, D-64287 D-64287 Darmstadt, \\ Germany. Corresponding author: Karlheinz Schaub; Phone: +49 (0) 615116 3489; Fax: +49 (0) 6151163488 ; \\ Schaub@iad.tu-darmstadt.de
}

\begin{abstract}
In industrialized countries musculoskeletal disorders (MSD) play an import role and are often responsible for almost one third of the total sick leave. The changes in the demographic profiles, i.e. aging work forces might even worsen this situation in the future. For a highly productive and sustainable use of human resources in production systems, ergonomics offers high potentials. In the recent years the authors have developed several ergonomic risk assessment tools, especially for the use in automotive industries. These methods may be used during the planning phases in the Tech Centers as well as during the production phase at shop floor level. The tools might also be used for a standardized communication in between the Tech Center and the plants to improve the effects of "lessons learned" for the design and layout of workstations and processes and the optimization of vehicle components. This paper describes suitable risk assessment tools as well as the integration of these tools into the vehicle development process. It introduces a comprehensive management approach for the integration of ergonomics into the management of production systems.
\end{abstract}

Keywords: ergonomic risk assessment tools, physical workload, musculoskeletal disorders, production systems, automotive industries

\section{Introduction}

Musculoskeletal disorders play an import role in industries and are responsible for more than one third of the total sick leave [1]. Besides this they generate high costs for companies and national economies. In Germany 2006, MSDs generated a loss of more than 400 million working days and a productivity loss of about 36 billion $€[1]$.

In Europe the protection of health \& safety at work is regarded as a public responsibility. The common European system of health and safety at work is mainly set up by the EU-Machinery Directive (2006/42/EC [2]) and EU-Framework Directive (89/391/EEC [3], including relevant Individual Directives e.g. the EU-Directive on manual materials handling 90/269/EEC [4]), which demand ergonomic risk analysis to be carried out in various phases of the product life cycle.
While in other regions of the world, governments do not implement national guidelines on health and safety at work, the companies are nevertheless responsible for the well being of their workforce and might face high compensation payments, if this fails.

Especially the Global Players in automotive industries have an intensive interest to have a global protection of their workforces; no matter if there are national or regional legislative requirements or not.

For these reasons, ergonomic risk assessments methods are needed to identify and evaluate health risks. Besides these, company internal processes are needed to tackle these risks.

The Institute of Ergonomics, Darmstadt University of Technology (IAD) has developed a set of risk assessment tools and a methodology how to integrate them into a company internal process that covers the whole product life cycle.

The risk assessment tools cover EU legal requirements and consider internationally accepted analysis 
tools for physical workload, which include also European and International ergonomic standards.

\section{Methods}

In a comprehensive company internal ergonomics process risk assessment tools act as a common platform for the company structures involved and support (legal) requirements for the ergonomic design and evaluation process (see figure 1).

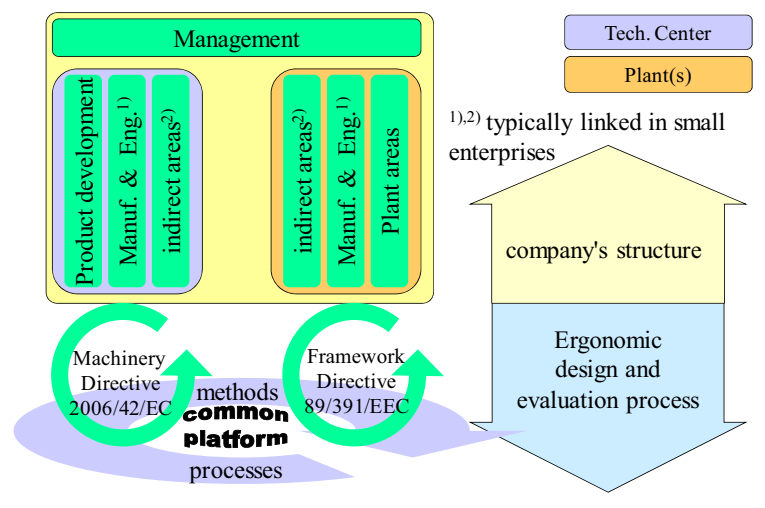

Fig. 1 Company internal ergonomic process considering the company's structure and EU legal requirements; risk assessment tools serve as a common platform

\subsection{Ergonomic risk assessment tools}

In order be able to perform intensive risk assessments for ALL workplaces (of a similar type)in a plant or for ALL processes or workstations designed in a Tech Center, a new generation of ergonomic screening tools had to be developed in order to keep the effort needed at an acceptable level.

The first German approach in this field was the FIOSH's (Federal Institute of Occupational Safety \& Health) Key Indicator Method (KIM) on manual material handling (repositioning, holding and carrying [5]).

In the following years the IAD developed a series of methods that allow the evaluation of physical workloads at shop floor level by means of screening tools. These tools are either workplace or operator oriented.

\subsubsection{Workplace oriented tools}

Workplace oriented methods are based on a workplace's geometric layout and the task required mechanical interaction (forces, moments, weights) and "forecast" a workload for a specific user population e.g. by means of DesignCheck [6] for a general European working population.

DesignCheck describes the operator's physical workload originated by working postures (and movements) with low physical effort, action forces, manual materials handling and repetitive loads of the upper limbs. Variations in body height lead to variations in body postures and consequently in the load level. With respect to the physical workload DesignCheck is able to consider neutral, male and female work forces.

\subsubsection{Operator oriented tools}

In accordance to the KIM and the Toyota [7] method, operator oriented IAD tools grant load points for ergonomically unfavorable conditions. Dependant on the score, a traffic light three zone rating system is associated with respect to the demands of the Machinery Directive (EN 614). In the following the recent development, the EAWS [8] is shortly desichibfdAWS [9] consists of four sections for the evaluation of working postures and movements with low additional physical efforts $(<30-40 \mathrm{~N}$ or $3-4 \mathrm{~kg}$ respectively), action forces of the whole body or hand-finger system, manual materials handling and repetitive loads of the upper limbs.

Sections one to three base their evaluation on physiological and biomechanical criteria; section four is based on medical and epidemiological data. With respect to the different evaluation approaches the results of sections one to three are combined to a "whole body" exposure, whereas section four indicates the load situation of the "upper limbs".

Both approaches are rated in a 3 zone rating system. The overall estimation is the worst case of "whole body" and "upper limbs".

The dashed line in between the green, yellow and red zones indicate, that they are no strict border lines, but transient areas. This means 47 and 53 points represent the same "orange" color, i.e. colors do not "switch from yellow to red", when crossing a score of 50 .

\subsection{Ergonomic company processes}

A successful application of ergonomic risk assessment tools requires company internal structures and processes. The kernel of the process is the ergonomic assessment tool that must be adapted to the company's need and trained. The following roll out may point out structural problems in a company so that a further development of company structure 
might be required. Awareness of ergonomic problems and their consequences is a further prerequisite for the success. Finally roles and responsibilities for the use of tools and the tracking of problems must be well defined and monitored.

\subsection{The $4+1$ concept}

Experiences of introducing ergonomic processes into various companies led to a so called "4 +1 concept" [10] as shown in fig 2 .

\begin{tabular}{|l|l|l|}
\hline \begin{tabular}{|l|l|}
\hline Introduction/Improvement \\
Risk assessment Tools
\end{tabular} & \\
\hline $\begin{array}{l}\text { Dissemination and Integrated Use } \\
\text { (Increase of Consistency) }\end{array}$ & \\
\hline $\begin{array}{l}\text { Formal integration into the entire } \\
\text { Product Realization Process }\end{array}$ & $\frac{0}{0}$ \\
\hline $\begin{array}{l}\text { Matching of Work Demands with Worker Abilities to achieve } \\
\text { „Ability-oriented Planning“ }\end{array}$ & $\frac{0}{0}$ \\
\hline
\end{tabular}

Fig. 2 Four steps aim to integrate ergonomics into an enterprise: introduction and roll out of assessments methods, integration into the product development process, ability oriented planning and the evaluation and control of the implementation process

The first process step is the introduction of a risk assessment tool. This step generates a company's awareness for ergonomic problems and shows the company's current state of art in ergonomics. This step includes the adaption of the tool to the company's needs and first training courses on the tool followed by try outs at the shop floor.

In a next step the tool has to be rolled out to all departments where ergonomics is of relevance. These two steps have to be monitored and controlled for effectiveness. For this purpose module 5 had to be developed and applied [11].

To use the benefits of lessons learned in a production system step 3, integration of ergonomic risk assessments in the product realization process, has to be performed. This helps to overcome reactive ergonomic design at shop floor level and enter a phase of highly efficient conceptive ergonomics in the product design and planning phase.

With respect to impaired people or changing demographic profiles, module 4 allows a better matching of operator abilities and workstation demands.

\section{Implementation / case studies}

After almost 15 years of development and design of ergonomic screening tools, several first level screening tools for the evaluation of physical workload are available. They had been tested and implemented in various companies [8].

They are easy applicable and comply with the requirements from secondary level analysis tools. They can be applied in the production as well as in the planning phase and serve as a communication tool in between the production and the development centers. Though the tools offer a first level screening their application is complex and not self explaining. Intensive training is required in order to ensure a proper application.

In order to control an effective implementation an ergonomic audit tool was developed and tested. The assessment of process outcomes enables managers to control the effectiveness of the implementation. The modular structure helps to quickly select appropriate and effective actions, the effectiveness of which could then be easily re-assessed [12].

\section{Discussion}

Before and while applying ergonomic screening tools, considerations should be made to limitations of these methods. Developed for applications in automotive assembly where short work cycles are predominant, the correct application should be considered when using these tools in longer work cycles (e.g. more than five minutes) or during acyclic work. For these situations in must be proofed that the load situations are almost equally distributed over the shift and prolonged high workload or load peeks are not present. The application of such screening tools cannot replace a detailed risk assessment as described in the secondary level analysis tools (e.g. European and International standards). The tools however can help to identify risks and prevent from applying secondary level tools, if the outcome of the assessment is clearly "green" or "red". In the first case no action is needed in the latter case redesign is required. The tools show what load situations should be lowered.

The management of ergonomics, however, has to face a particular challenge: Most of the desired results, i.e. less work-related musculoskeletal disorders, higher employee satisfaction and a sustainable as well as effective use of the human resource within the production system are subject to multi-causal influences and long time gaps between cause (ergo- 
nomic risks) and effect (injuries, impairments). That is why absenteeism, injury-rates or employeesatisfaction cannot simply be used as control indicators for a successful implementation of ergonomic work conditions.

Instead, evaluation has to be focused on systematic risk reduction in terms of a total ergonomics management. The conducted audits showed that an audit is a highly accepted method which allows to quickly assess the organization and processes concerned with ergonomic risks.

\section{References}

[1] Elke Schneider and Xabier Irastorza, Work-related musculoskeletal disorders in the EU - Facts and figures, European Agency for Safety and Health at Work, 2010, ISBN 978-929191-261-2,

http://osha.europa.eu/en/publications/reports/TERO09009EN $\mathrm{C} /$ view? searchterm $=$ None

[2] DIRECTIVE 2006/42/EC OF THE EUROPEAN PARLIAMENT AND OF THE COUNCIL of 17 May 2006 on machinery, and amending Directive 95/16/EC (recast), Official Journal of the European Union, L 157/24, 9.6.2006 http://eur-

lex.europa.eu/LexUriServ/LexUriServ.do?uri=OJ:L:2006:157: 0024:0086:EN:PDF

[3] Council Directive 89/391/EEC of 12 June 1989 on the introduction of measures to encourage improvements in the safety and health of workers at work, Official Journal of the European Union, No. L 183/1, 29.6.1998

[4] Council Directive 90/269/EEC of 29 May 1990 on the minimum health and safety requirements for the manual handling of loads where there is a risk particularly of back injury to workers (fourth individual Directive within the meaning of Article 16 (1) of Directive 89/391/EEC), Official Journal of the European Union, No. L 156/9, 21.6.1990

[5] Steinberg, U.; Caffier, G.; Liebers, F.: Assessment of Manual Material Handling based on Key Indicators - German Guide- lines. In: Handbook of Standards in Ergonomics and Human Factors. Ed. by W. Karwowski. Lawrenz Erlbaum Associates. Mahwah, New Jersey, London 2006. S. 319-338. ISBN 08058-4129-6

[6] Schaub, K.; Winter, G.; Landau, K.: Design Check - A Pilot Study for the Evaluation of Assembly Tasks in Automotive Industries. In: Proceedings of the International Conference on Computer- Aided Ergonomics and Safety, Barcelona, Spain, 19 - 21. May 1999

[7] Koide, I.: Development of TOYOTA Method of Function Evaluation (Workload Evaluation). In: Toyota Engineering (1990), Vol. 40, No 2; Nov., S. 258-265.

[8] Schaub, K.; Landau, K.; Bruder, R.: Development and application of methods for stress analysis in manufacturing. In: (CD-Rom) AHFE International Conference, 2nd International Conference on Applied Human Factors and Ergonomics 2008, July 14-17, 2008, Caesars Palace - Las Vegas, Nevada USA, Louisville (KY) 2008

[9] Schaub, K.; Caragnano, G.; Britzke, B.; Bruder, R.: The European Assembly Worksheet. In: Mondelo, P.; Karwowski, W.; Saarela, K.; Swuste, P.; Occhipinti, E. (Hrsg.): Proceedings of the VIII International Conference on Occupational Risk Prevention. ORP 2010, Valencia 5.-7.5.2010. ISBN: 978-84934256-8-5

[10]Bruder, R., Rademacher, H., Schaub, K., and Geiss, C. (2009) "Modular Concepts for Integrating Ergonomics into Production Processes", in: Industrial Engineering and Ergonomics: Visions, Concepts, Methods and Tools, Schlick, C. (Ed.). pp. 385-396.

[11]Bierwirth, Max ; Bruder, Ralph ; Schaub, Karlheinz, Karwowksi, Waldemar ; Salvendy, Gavriel (eds.) : Total Ergonomics Management: A Modular Concept for the Integration of Ergonomics into Production Systems. In: Advances in $\mathrm{Hu}-$ man Factors, Ergonomics, and Safety in Manufacturing and Service Industries. CRC Press, Boca Raton (USA, Florida) 2010, pp. 108-118. ISBN 978-1-4398-3499-2

[12]Bierwirth, Max ; Bruder, Ralph ; Schaub, Karlheinz: Management Audit to Implement Effective Ergonomics in Manufacturing Companies. In: 10. International Symposum on $\mathrm{Hu}-$ man Factors in Organisational Design and Management, 4. - 6. April 2011, Grahamstown (South Africa) 